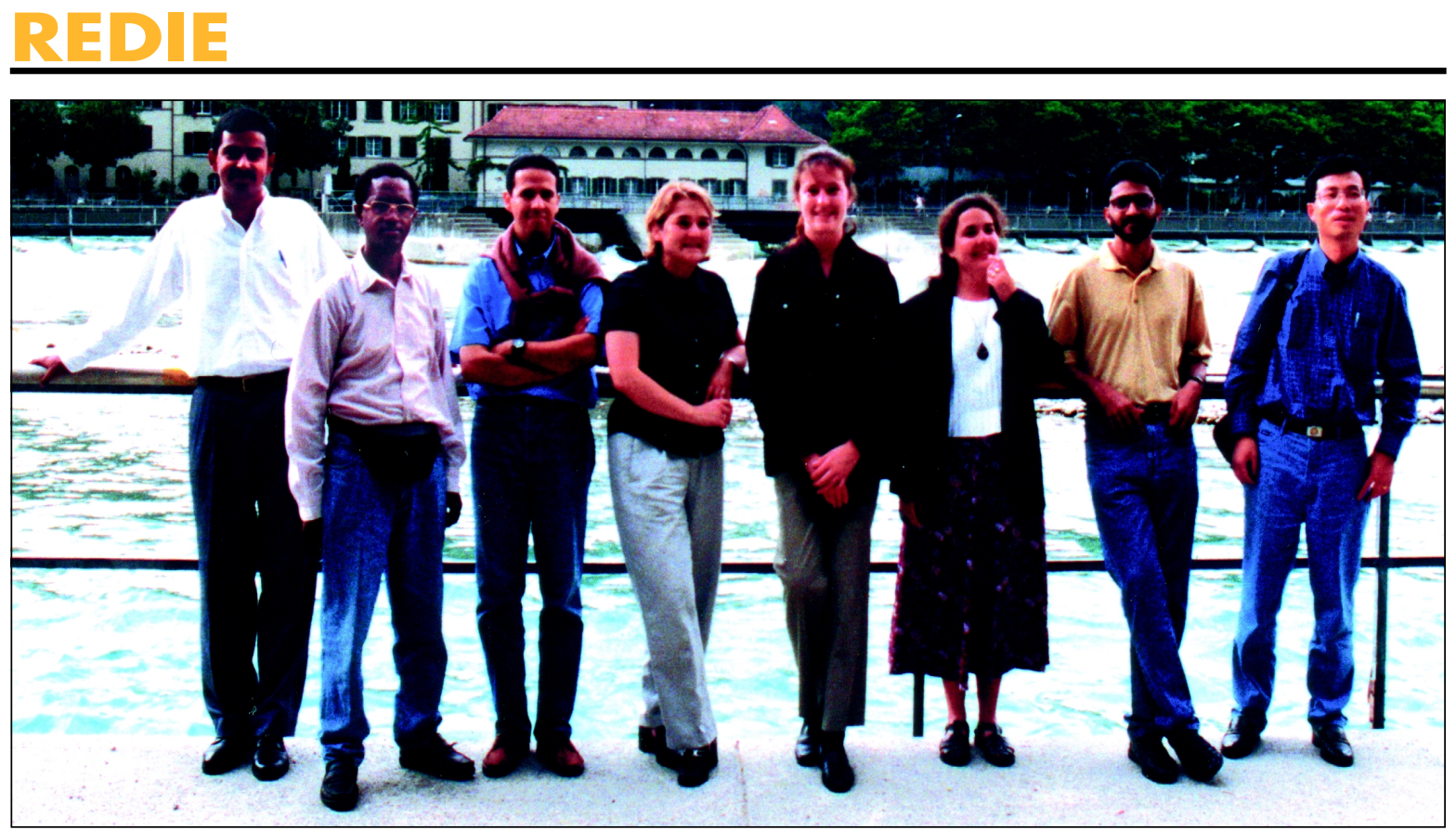

The PAGES/START fellows during their stay in Bern (left to right): P.J. Thomas, M.U. Mohammed, B. Damnati, S. Dannenmann (US-NSF fellow), A. Mulock-Houwer, G. Bernal, M. Thamban, Y. Yin. In the background the remnants of the 1999 spring flood, a magnitude last observed in 1566.

\title{
EDITORIAL
}

\section{Ready for REDIE}

One of the named Activities in the PAGES Implementation Plan focuses on 'Regional, Educational and Infrastructure Efforts' (REDIE). This reflects a foresighted view among the founders of PAGES that our future legacy should include not only data and scientific understanding, but also human development. The urgent need to establish scientific priorities and devise ways of realizing and coordinating them has taken precedence and REDIE has taken second place - until now. This summer (July 17-24), a formidable group of leading paleo-scientists from around the world will give a summer school entitled "The Dynamics of the Earth System: Processes and Records of Past Climate Change" (see http://phkup0.unibe.ch/summer/). One outcome of discussions between the PAGES IPO and the organizers of the summer school, Thomas Stocker and Andy Lotter, has been a scheme to fund attendance by young scientists from developing countries. START, the 'Global Change System for Analysis, Research and Training', that has responsibilities for capacity building across the range of themes embraced by IGBP, IHDP and WCRP, has joined PAGES to finance participation in the course by researchers from China, Ethiopia, India, Mexico, Morocco and South Africa (see announcement on page 2). Those attending the course will also spend a week in Bern organized by the PAGES IPO. In selecting from the many promising applications received, we asked ourselves the following questions:

1. Can we offer scholarships to at least one candidate linked to each of the PEP transects and thus ensure the best regional coverage? (happily, the answer to this was 'yes'; we received high quality applicants from researchers working within each transect)

2. Is the candidate likely to feed his/her knowledge and experience back into the region?

3. Do the motivation, experience and goals of the candidate indicate an ability to connect with and benefit from the course as planned?

continued on next page

1 REDIE Editorial, Winners of Summer School Fellowships, Educational Opportunities

3 Workshop Announcements Fall AGU, IDEAL, International Geological Congress, IMAGES

4 Program News Environmental Change and Nonlinearity, DIRTMAP

6 Workshop Reports Loessfest'99, LUCC-PAGES-DIS, ITASE, Taiwan Conference, Chinese Lakes, Varve 99

14 Science Highlights Varved Sediments in Fennoscandia, Monsoon Impacts on El Niño, Boreholes

Last Page Have you seen..., Calendar 
Editorial, continued from front page

We hope to build on the experience gained from this first PAGES-initiated REDIE activity and thereby develop an ongoing program of capacity building within the PAGES research community. The PAGES Scientific Steering Committee has agreed that up to $\$ 10 \mathrm{k}$ should be devoted to REDIE each year, at the discretion of the Executive Committee and in response to carefully developed proposals. In order to make the best possible use of this for future generations of young scientists from developing countries, we shall need the feedback and advice from our first group of funded summer school participants. We also invite ideas and advice from the wider PAGES community, especially those working in developing countries whose experience is relevant to our initiative. We look forward to receiving your suggestions. A sustained and well conceived investment in the next generation of researchers is our goal. Without that the PAGES past has no future.

\section{Frank Oldfield}

PAGES International Project Office, Bern, Switzerland oldfield@pages.unibe.ch

\section{Winners of Swiss Summer School Fellowships}

PAGES and START are pleased to announce fellowship awards to 8 scientists from developing countries to attend the Swiss Summer School "The Dynamics of the Earth System: Processes and Records of Past Climate Change." The names and poster titles of the winners, as well as three runner-up finalists are listed below.

\section{Winners}

G. Bernal, Mexico

Oceanic variability and biogenic sediment accumulation patterns in the subtropics for the last 4 centuries: records from laminated sediments in the lower Gulf of California.

B. Damnati, Morocco

Palaeoclimatic reconstructions for the last $30 \mathrm{ka}$ in Africa.

M. Thamban, India

Sedimentological investigation along the western continental margin of India: Inferences on palaeocanography during the late Quaternary.

M.U. Mohammed, Ethiopia

Pollen and charcoal indicators of recent land-use change in the Ethiopian rift valley.

\section{A. Mulock-Houwer, South Africa}

Late Quaternary environmental reconstruction and climate modeling in the winter rainfall region of the Western Cape, South Africa.

P.J. Thomas, India

Climatic changes in the Anantapur arid zone observed in the last 500 years - an integrated study.

A. Yeshanew, Ethiopia

Signals of atmospheric dynamics in Africa.

Y. Yin, China

Evolution and variability of the Indian monsoon, climatic records from lacustrine and deep sea deposits and coupling with the East Asian monsoon during the last $60 \mathrm{ka}$.

\section{Finalists}

\section{I.O. Adelekan, Nigeria}

Spatio-temporal variations in the synoptic origin of rainfall over Nigeria.

C. Gray, South Africa

A record of terrestrial environmental change from marine cores of the

Namaqualand mudbelt in southern Africa.

F. Mwaura, Kenya

The geographical characteristics of past lacustrine surfaces in the Eastern

Rift Valley, Kenya.

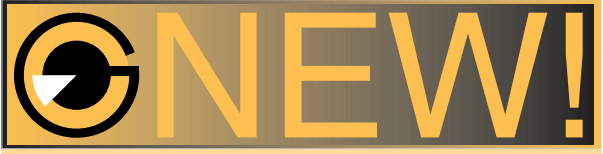

\section{Educational Opportunities}

This is a new feature in our newsletter which supports the PAGES REDIE task discussed in the editorial in this issue. It is aimed at alerting PAGES readers to educational opportunities around the world in paleoenvironmental science. Further details, including internet links are maintained on the PAGES website (http://www.pages.unibe.ch/activities/ redie.html). Comments and suggestions for material to be included should be sent to Keith Alverson (alverson@ pages.unibe.ch).

\section{MSc in Paleoecology}

School of Archeology \& Paleoecology Queen's University of Belfast, UK http://www.qub.ac.uk/arcpal/

\section{MSc Recent Environmental Change}

Department of Geography

University of Liverpool, UK http://www.liv.ac.uk/Geography/ Html_use/pgcourse3/rec.html

\section{M.Res in Aquatic Environmental Change}

Environmental Change Research Centre University College London, UK http://www.geog.ucl.ac.uk/ecrc/mres.htm

\section{MSc in Quaternary Science}

Centre for Quaternary Research

Royal Holloway University of London and

Environmental Change Research Centre University College London, UK http://glacier.gg.rhbnc.ac.uk/mscdegree.html

\section{PA(3ES Newsletter 99-2}

Editors: Keith Alverson and Frank Oldfield Layout: Niklaus Schranz Circulation: 3000

The PAGES International Project Office and it's publications are supported by the Swiss and US National Science Foundations

Printed on recycled paper 